\title{
The Variation in Poisson's Ratio Caused by Interactions between Core and Wrap in Helical Composite Auxetic Yarns
}

\author{
S. Bhattacharya, G.H. Zhang*, O. Ghita, K.E. Evans \\ College of Engineering, Mathematics and Physical Sciences, University of Exeter, North Park Road, Exeter EX4 4QF, UK \\ *Corresponding author-mail address: G.Zhang@exeter.ac.uk. Tel: +44 (0) 1392263617.
}

\begin{abstract}
Materials with a negative Poisson's ratio are referred to as auxetic. One recently invented example of this is the helical auxetic yarn (HAY). This has been proved to successfully exhibit auxetic behaviour both as a yarn and when incorporated into fabric. The HAY is based on a double-helix geometry where a relatively stiffer 'wrap' is helically wound around a compliant core fibre. This paper studies the effect of the interaction between the core and the wrap fibre on the auxetic behaviour of the HAY, including the effect of their relative moduli. Assessment of the Poisson's ratio of the HAYs has revealed that an elevated difference in component moduli causes the wrap fibre embedding itself into the core fibre, thus decreasing the auxetic effect. Careful determination of an optimum core-wrap moduli ratio where the ratio is high enough to yield an auxetic effect and low enough to prevent the core-indentation effect can lead to the fabrication of a yarn with largest negative Poisson's ratio.
\end{abstract}

Keywords: A. Fibres; A. Flexible composites; A. Functional composites; B. Mechanical properties; C. Deformation. 


\section{Introduction}

'Auxetic' materials are a relatively new class of functional materials which exhibit negative Poisson's ratio; i.e. an applied tensile strain in the longitudinal direction results in a positive strain in the transverse direction[1]. Such materials have many benefits such as increased shear to tensile stiffness ratios, indentation resistance, energy absorption and the ability to form synclastic doubly-curved surfaces[2-4]. A range of auxetic materials have been discovered, fabricated and investigated during the last two decades, including auxetic cellular solids[5, 6], auxetic microporous polymers [7, 8], auxetic composites[9-11], molecular auxetic materials $[1,12,13]$.

Hook et. al. proposed a new geometry and composite for auxetic behaviour in the form of a helically wound yarn which can attain large negative Poisson's ratio, both by itself and in a textile[14]. This has been referred as the helical auxetic yarn (HAY), and may find applications in filtration[15] and healthcare[16]. Its basic structure and mechanics has been well investigated, both experimentally and theoretically, since its invention [10, 11, 17-19]. Owing to its wide variety of applications, research is continuing on improving its performance. Some more types of auxetic fibres have been fabricated by other researchers for textiles [20-22]. This study deals with some aspects of the HAY which reveals that an alteration of material parameters can cause large changes in its negative Poisson's ratio.

A HAY is composed of two conventional fibres in which a relatively stiffer and thinner "wrap" fibre is helically wound around a more compliant and thicker "core" fibre, as shown in Fig. 1a. On application of longitudinal strain, the difference in the modulus of elasticity and diameters of the two fibres causes lateral displacement of the core by the wrap, resulting in an overall lateral expansion of the yarn's maximal width. By selecting fibre diameters, 
moduli and the initial geometry of the HAY, a large negative Poisson's ratio can be generated.

The configuration of a HAY requires the core to be more flexible than the wrap. If the core is both compliant and elastomeric the core performs two functions: enabling large lateral deformation when strain is applied, and acting as a 'return spring' to recover its former position and reform the original helix in the wrap when the load is removed. However, with the compliancy of the core there is the possibility of generating an undesirable mechanism within the HAY. When the HAY is under tension the wrap may indent the surface of the core and embed itself into the core. As a consequence, there may be a reduction in the negative Poisson's ratio and hence the auxetic behaviour of the HAY. Some of the possible interactions are illustrated in Fig. 1b.

These core-indentation effects depend on the relative moduli of the core and wrap and, at large deformation, the extent to which the core remains elastic or goes plastic. In previous research studies, auxetic behaviour has been demonstrated by HAYs with varying ranges of core and wrap materials and has also been observed to be strongly dependent on relative component moduli. Sloan et. al. fabricated a HAY using polyurethane fibre as the core (Young's modulus $30 \mathrm{MPa}$ ) and polyamide fibre as the wrap (Young's modulus $3.4 \mathrm{GPa}$ ). This HAY demonstrated a Poisson's ratio as low as-2.7 for the yarn with $13^{\circ}$ wrap angle[18]. Miller et. al. fabricated a HAY using polyurethane fibre as core (Young's modulus $53 \mathrm{MPa}$ ) and ultra-high molecular weight polyethylene fibre as wrap (Young's modulus $6 \mathrm{GPa}$ ) and obtained a Poisson's ratio of -2.1[10]. Miller et. al. fabricated the HAY using nylon fibre as the core (Young's modulus 1.6GPa) and carbon fibre as the wrap (Young's modulus 143GPa) 
which demonstrated Poisson's ratios of $-5.8,-2.3$ and -1.1 for $10^{\circ}, 20^{\circ}$ and $30^{\circ}$ wrap angles[11] respectively.

In this paper we explore the effect of core-indentation effects on the auxeticity of the HAY by investigating a range of HAYs with various core moduli but the same wrap modulus and examining the resultant cross-sectional deformation of core and wrap.

\section{Experimental Methods}

Six types of HAYs were fabricated for core-indentation effect studies and subsequently named as yarns A, B, C, D, E and F. Helical auxetic yarns were manufactured using a bespoke spinner mechanism as described earlier [18]. Approximately $10 \mathrm{~m}$ of yarn were fabricated for each HAY type. According to previous works [17-19], the lower initial wrap angle of the HAY offers better auxetic performance. Therefore, a low initial wrap angle of approximately $12^{\circ}$ was maintained for all HAYs in this work.

The yarn components and the material properties of the component fibres are summarized in Table 1. Mechanical testing of fibre and yarn samples were carried out according to ASTM D3822-07 - tensile properties of single textile fibres [23].

\subsection{Sample preparation for cross section analysis of the HAY}

The cross section analysis was carried out under optical microscope in order to investigate the core indentation effect of the HAY. A $70 \mathrm{~mm}$ length of each HAY was inserted through a glass pipette and the setup was mounted in a Lloyd instruments-EZ 20 tensile testing machine under one specific load. Epoxy resin was then carefully poured into the pipette and the bottom of the pipette was sealed. The epoxy was allowed to cure for a period of 12 hours. 
The HAY under specific load was thus embedded in the resin and the yarn was frozen at the strain generated at that load. After removal of the load, the yarn retained that strain. The sample was cut in the transverse direction (normal to the applied load), polished and the cross section of the HAY was investigated under optical microscope with 60 times magnification. For the sake of convenience, this shall be referred as 'cross sectional image'. Three yarn samples were prepared for each load value, and specific loads were selected to cover the entire load range between zero load and failure point of each HAY. The applied load values are summarized in Table 2. Cross-sectional images under zero load were not considered, as the wrap and the core would become loose and would lose their wrapping angle. A small amount of tension is required in order to maintain the HAY's characteristics.

2.2. Study of deformation of the core and wrap caused by the wrap in the ideal case (no coreindentation effect in the HAY)

The cross-sectional images obtained from the process described above will be used to study core indentation effect of the yarn. In order to determine the auxetic effect in the ideal case, the length of the wrap embeds into the core was measured (Fig. 1c). When this length is added to the diameter of the yarn to compensate the losing net width of the yarn due to core indentation effect, then hypothetical diameter of the yarn with no core indentation effect is obtained. Image $\mathbf{J}$ software was used for the length measurement. The known diameter of the core was obtained through SEM image and was used for calibration.

\subsection{Determination of Poisson's ratio of the HAY}

Once all the tests had been carried out, the Poisson's ratio of each HAY was determined through three separate methods: (1) Longitudinal and transverse strain was obtained by a high magnification, non-contact video system, coupled with Lloyd Instruments (www.lloyds- 
instruments.co.uk) EZ 20 tensile tester. Tensile measurements under displacement control were performed with a $500 \mathrm{~N}$ load cell at a speed of $5 \mathrm{~mm} / \mathrm{min}$. Gauge lengths were $70 \mathrm{~mm}$ for all yarns. Meanwhile, the images were captured at regular strain intervals by a $4.9 \mathrm{MP}$ digital camera (Edmund Optics EO-5012C USB). For the sake of convenience these images shall be referred as 'external images'; (2) Transverse strain obtained from the cross sectional images that were processed by the method in the section 2.1 , and longitudinal strain obtained from the external images under the same load; (3) Transverse strain of the hypothetical yarn with no core-indentation effect at a specific load was determined using the modified crosssectional images through the method in the section 2.2, and longitudinal strain was obtained from the external images at the same load. Thus the Poisson's ratio was determined for the ideal case when there is no core indentation occurring. If there is no core indentation effect occurs for any of these HAYs, their Poisson's ratio will be determined only by the first method. Image analysis and strain measurements for these HAYs were performed based on Sloan et al.'s previous work [18].

Finally, the Poisson's ratio for yarns was calculated using the obtained engineering strains $\varepsilon_{y}$ and $\varepsilon_{x}$.

$v_{x y}=-\frac{\varepsilon_{y}}{\varepsilon_{x}}$

Where $v_{x y},{ }_{z y}$, and $\varepsilon_{x}$ are the Poisson's ratio, transverse strain and longitudinal strain of the HAY.

\section{Results and Discussion}

\subsection{Yarn A}

This yarn comprises a PU core with a relatively large, multi-filament wrap. External and cross-sectional images of the yarn A under the same load were compared and the Poisson's 
ratio of the yarn was analysed. Figs. $2 \mathrm{a}-2 \mathrm{j}$ show the external and cross-sectional images which were taken under $6,15,30,40$ and $48 \mathrm{~N}$ load for yarn A respectively. Fig. 2a indicates that the yarn under $6 \mathrm{~N}$ load shows no core-indentation phenomenon. The wrap starts to embed into the core when $15 \mathrm{~N}$ load is applied (see Fig. 2c), and the degree of indentation increases with an increase of load (see Figs $2 \mathrm{e}, 2 \mathrm{~g}$ and $2 \mathrm{i}$ ).

Figure 3 presents a comparative analysis of the Poisson's ratio of yarn A obtained through all three methods described in the section 2.3. A sharp increase in the Poisson's ratio at low strains is initially observed followed by a significant decrease in Poisson's ratio due to the wrap fibre conforming to the unstrained core. Similar phenomena have been reported in previous study[18]. It can be seen that the Poisson's ratio obtained through the first two methods are nearly the same, as expected. For the ideal case where it is assumed that there is no core-indentation effect, there is an obvious augment in negative Poisson's ratio, then the auxetic effect of the HAY decreases as a result of an increased core-indentation effect. It is clear that the magnitude of the auxetic effect is diminished by the indentation.

In order to test whether there was any shrinkage of the HAY caused by the resin, the diameter of the same HAY was measured by the external and the cross-sectional images, respectively. The results are presented in Table 3. It can be seen that there is no obvious shrinkage of the HAY due to embedding into the resin; hence this factor was ignored during further analysis.

Core-indentation effect may be attributed to the lower Young's modulus of PU core relative to the UHMWPE wrap. In order to assess these phenomenon further, core fibres with higher Young's moduli were chosen for fabrication of yarns B, C and D while using the same UHMWPE wrap fibre. 


\subsection{Yarn $B$}

Higher modulus polyamide fibre was used for core for fabrication of yarn B and the same experiments were carried out. Figs. 4ashow the cross-sectional images captured with 60 times magnification under 10, 30, 50 and $70 \mathrm{~N}$ load respectively. The external images of the yarn were also obtained at the same time; however, they are not included in the paper as visually they do not add further insights into the indentation phenomenon.

The above cross-sectional images clearly show that there is no core-indentation effect for yarn B. Hence the Poisson's ratio was determined only through external images, and a maximum negative Poisson's ratio of -1.67 was obtained at strain of 0.09 . It is also visible that the cross-section of the core is not circular, but pentagonal.

\subsection{Yarn $C$}

For fabrication of yarn $\mathrm{C}$, the core was replaced with PE. Figs. $4 \mathrm{~b}$ show the images of cross section of the yarn captured with 60 times magnification under 20, 35, 50 and $65 \mathrm{~N}$ load respectively. It is interesting to note that there is no core-indentation phenomenon as well for this sample. The maximum negative Poisson's ratio determined through the external images was obtained to be -2.22 at strain of 0.06 .

\subsection{Yarn D}

For fabrication of yarn D, the core was replaced with elastomeric polyester (PET). Figs. 4c show the cross sectional images captured with 60 times magnification under 15,30 and $45 \mathrm{~N}$ load respectively. In this case as well, there is no core-indentation effect appearing for yarn D. The maximum negative Poisson's ratio determined through external images was obtained to 
be -13.5 at strain of 0.02 . It is noted that a multi-filament yarn may spread around the core, thus spreading the load.

Figure 5 shows the Poisson's ratio of all the four yarns. Yarn A has the least auxetic behaviour and least negative Poisson's ratio of -1.65 ; which can be attributed to coreindentation effect. The maximum negative Poisson's ratio of yarn $\mathrm{B}$ is -1.67 ; hence it can be concluded that the modulus of PA core relative to UHMWPE wrap presents a limit where the core is elastic enough to show reasonable auxetic behaviour and stiff enough to mitigate or circumvent core-indentation effect. The yarn with PET core (yarn D) shows the highest auxetic effect, with a maximum negative Poisson's ratio of -13.52 . Further rise in modulus of the core in yarn $\mathrm{C}$ results into decrease in auxetic effect with maximum negative Poisson's ratio of -2.22 . Yarn B holds the least core Young's modulus among yarn B, C and D, but contrary to expectation, it shows the least auxetic effect. This can be attributed to other factors such as component diameter and pentagonal cross-section of the core. The performance of the HAY can be affected by a series of design parameters, such as core/wrap diameter ratio and core/wrap tensile modulus ratio [17].

\subsection{Yarn $E$ and $F$}

The UHMWPE fibre that has been used as wrap in all HAYs discussed above (Yarn A, B, C and D) is a multifilament. A further comparison was made using a lower stiffness monofilament wrap - a co-polymer polyamide fibre. Therefore, Yarn E was fabricated with PU core which is the core fibre showing a strong core-indentation effect. The same experiments were carried out as for yarns A, B, C and D. Fig. 6 shows the micrographs of the two wrap fibres. 
The cross sectional images of yarn E captured with 60 times magnification under 7 and $15 \mathrm{~N}$ load are shown in Fig. 7a and it indicates no core indentation effect. Fig. 7b shows comparison between cross section of yarn $\mathrm{A}$ and $\mathrm{E}$, which has monofilament and multifilament wraps, respectively. It is obvious that unlike UHMWPE, co-polymer polyamide does not cause any indentation in the PU core; as a result of wrap's lower Young's modulus. Figure 8 presents a comparative analysis of Poisson's ratio of yarn A and, which are comprised of PU core and monofilament and multifilament wrap fibres. The negative Poisson's ratio of the yarn with PU core is much higher for co-polymer polyamide wrap compared to UHMWPE wrap. The maximum negative Poisson's ratio of yarn A is -1.65 where as that of yarn E is -5.58. Yarn E shows larger auxeticity compared to yarn A in spite of a much lower modulus of the wrap fibre.

Since yarn D with the PET core showed the largest negative Poisson's ratio among others, hence, its multifilament wrap was replaced with a monofilament co-polymer polyamide fibre to fabricate Yarn $\mathrm{F}$ for further investigation. Figs 9a show the cross sectional images of Yarn F captured with 60 times magnification under 10, 15 and $20 \mathrm{~N}$ load. Figure $9 \mathrm{~b}$ shows comparison between cross section of yarn D and F. It clearly shows that both wrap fibres do not cause any indentation in the PET core, which can be attributed to high Young's modulus of the PET core. In comparison to PU, PET is stiff enough to prevent any core-indentation occurring in the yarn.

It is also interesting to note that the contact surface area between core and wrap of Yarn A is much smaller than that of Yarn D under the same load (15 N) in Figs. $7 b$ and 9b, respectively. Hence, in comparison to the Yarn D, core indentation effect is more likely to occur in the Yarn A due to higher localized stress on the core fibre from the wrap fibre. The wider spread 
of multifilament wrap around the core is not always consistent as the other yarns. This can be due to various reasons:1) different surface roughness of the two core fibres; 2) stiffness values of the two core fibres; 3 ) multifilament wrap fibres are not bundled very well.

A comparative analysis of Poisson's ratio of yarn D and F are shown in Fig. 10. Yarn D gives different a much better auxetic behaviour than yarn F. In addition, the maximum negative Poisson's ratio of yarn D is also much larger than yarn $\mathrm{F}$. Therefore, in case of no coreindentation effect occurring of the HAY, multifilament and high stiffness wrap fibre gives a better auxetic behaviour. This result is demonstrated by comparing the results in Figs. 9b and 10. The mechanical properties of all core, wrap and yarns are presented in an increasing order of core Young's modulus in Table 4. The Young's modulus of PU is lower than that of other core fibres and is extremely low compared to that of the wrap $(21.96 \mathrm{GPa})$; hence the core-indentation effect may be assumed to be the consequence of this variation in core Young's modulus. A rise in modulus of core fibre has resulted in exclusion of this effect. Yarn D gives the best auxetic effect among others.

\section{Conclusions}

This paper explores the effect of a core-indentation phenomenon on the performance of helical auxetic yarns. Analysis of the cross-section of a series of strained yarns showed that large differences between the component moduli results into significant deformation of the core fibre by the wrap fibre. Core-indentation phenomenon renders a large negative effect on the auxetic behaviour of the yarn. In this work, a chain of experiments has been carried out to determine a limit where the relative component moduli is high enough to demonstrate auxetic effect and low enough to prevent core-indentation effect occurring. The structure of the wrap fibre has also been observed to be crucial in originating core-indentation. The multifilament 
wrap fibre has a different core-indentation mechanism than the monofilament fibre on the yarn; therefore, it indicates that choosing an appropriate wrap fibre is essential to optimise auxetic behaviour of the yarn. Overall, the negative Poisson's ratio is maximised if the wrap is much stiffer than the core provided that indentation does not occur. Indentation will occur if the wrap is too stiff. Appropriate combination of component moduli and geometric parameters has facilitated the fabrication of the HAY with large negative Poisson's ratio of 13.52. This work gives a significant guidance to tailor auxetic behaviour of helical auxetic yarns for their particular applications.

\section{Acknowledgements}

This work is supported by the UK Engineering and Physical Science Research Council (EPSRC grant No. EP/J004553/1). The authors would like also to acknowledge the industrial collaborators - Auxetix Ltd., Wisla Narrow Fabrics Ltd and Fothergill Engineered Fabrics Ltd.

\section{References}

[1] Evans KE, Nkansah MA, Hutchinson IJ, Rogers SC. Molecular network design. Nature. 1991;353(6340):124-124.

[2] Evans KE, Alderson A. Auxetic Materials: Functional Materials and Structures from Lateral Thinking! Advanced Materials. 2000;12(9):617-628.

[3] Yang W, Li Z-M, Shi W, Xie B-H, Yang M-B. Review on auxetic materials. Journal of Materials Science. 2004;39(10):3269-3279.

[4] Liu Y, Hu H. A review on auxetic structures and polymeric materials. Scientific Research and Essays. 2010;5(10):1052-1063.

[5] Lakes R. Foam Structures with a Negative Poisson's Ratio. Science. 1987;235(4792):1038-1040. 
[6] Huang X, Blackburn S. Developing a New Processing Route to Manufacture Honeycomb Ceramics with Negative Poisson's Ratio. Key Engineering Materials. 2002;206-213:201-204.

[7] Caddock BD, Evans KE. Microporous materials with negative Poisson's ratios. I. Microstructure and mechanical properties. Journal of Physics D: Applied Physics. 1989;22(12):1877.

[8] Cai Z, Zhang Y, Li J, Xue F, Shang Y, He X, et al. Real time synchrotron SAXS and WAXS investigations on temperature related deformation and transitions of $\beta$-iPP with uniaxial stretching. Polymer. 2012;53(7):1593-1601.

[9] Evans KE, Caddock BD. Microporous materials with negative Poisson's ratios. II. Mechanisms and interpretation. Journal of Physics D: Applied Physics. 1989;22(12):1883.

[10] Miller W, Hook PB, Smith CW, Wang X, Evans KE. The manufacture and characterisation of a novel, low modulus, negative Poisson's ratio composite. Composites Science and Technology. 2009;69(5):651-655.

[11] Miller W, Ren Z, Smith CW, Evans KE. A negative Poisson's ratio carbon fibre composite using a negative Poisson's ratio yarn reinforcement. Composites Science and Technology. 2012;72(7):761-766.

[12] He C, Liu P, Griffin AC. Toward Negative Poisson Ratio Polymers through Molecular Design. Macromolecules. 1998;31(9):3145-3147.

[13] Grima JN, Jackson R, Alderson A, Evans KE. Do Zeolites Have Negative Poisson's Ratios? Advanced Materials. 2000;12(24):1912-1918.

[14] Hook PB, Evans KE, Hannington JP, Hartmann-Thompson C, Bunce TR. Composite Materials and Structures, U.S. Patent No. US2007031667. 2007.

[15] Hook PB. Uses of Auxetic Fibres. US Patent No US20070210011 A1, 2007.

[16] Hook PB. Composite fibre and related detection system. US Patent No US20090193906 A1, 2009. 
[17] Wright JR, Sloan MR, Evans KE. Tensile properties of helical auxetic structures: A numerical study. J Appl Phys. 2010;108(4).

[18] Sloan MR, Wright JR, Evans KE. The helical auxetic yarn - A novel structure for composites and textiles; geometry, manufacture and mechanical properties. Mechanics of Materials. 2011;43(9):476-486.

[19] Wright JR, Burns MK, James E, Sloan MR, Evans KE. On the design and characterisation of low-stiffness auxetic yarns and fabrics. Textile Research Journal. 2012;82(7):645-654.

[20] Alderson KL, Alderson A, Smart G, Simkins VR, Davies PJ. Auxetic polypropylene fibres:Part 1 - Manufacture and characterisation. Plastics, Rubber and Composites. 2002;31(8):344-349.

[21] Ravirala N, Alderson A, Alderson KL, Davies PJ. Expanding the range of auxetic polymeric products using a novel melt-spinning route. physica status solidi (b). 2005;242(3):653-664.

[22] Ugbolue SC, Kim YK, Warner SB, Fan Q, Yang C-L, Kyzymchuk O, et al. The formation and performance of auxetic textiles. Part I: theoretical and technical considerations. The Journal of The Textile Institute. 2010;101(7):660-667.

[23] ASTM. D 3822-07. Standard Test Method for Tensile Properties of Single Textile Fibers. 2007. 
Table 1. Specifications of HAYs fabricated for core-indentation study and material properties of the component fibres.

\begin{tabular}{|c|c|c|c|c|c|}
\hline Yarn & Core & Wrap & Fibre type & $\begin{array}{l}\text { Fibre diameter }(\mathrm{mm}) \\
(+/-0.01 \mathrm{~mm})\end{array}$ & $\begin{array}{l}\text { Fibre Young's } \\
\text { Modulus } \\
(\mathrm{MPa})\end{array}$ \\
\hline A & Polyurethane (PU) & $\begin{array}{l}\text { Ultra-high-molecular-weight } \\
\text { polyethylene (UHMWPE) }\end{array}$ & $\begin{array}{l}\text { Monofilament core and } \\
\text { multifilament wrap }\end{array}$ & $\begin{array}{l}\text { Core: } 0.65 \\
\text { Wrap: } 0.23\end{array}$ & $\begin{array}{l}\text { Core: } 114 \pm 20 \\
\text { Wrap: } 21960 \pm 1200\end{array}$ \\
\hline B & Polyamide 12 (PA) & UHMWPE & $\begin{array}{l}\text { Monofilament core and } \\
\text { multifilament wrap }\end{array}$ & $\begin{array}{l}\text { Core: } 1.06 \\
\text { Wrap: } 0.23\end{array}$ & $\begin{array}{l}\text { Core: } 260 \pm 40 \\
\text { Wrap: } 21960 \pm 1200\end{array}$ \\
\hline $\mathrm{C}$ & Polyethylene (PE) & UHMWPE & $\begin{array}{l}\text { Monofilament core and } \\
\text { multifilament wrap }\end{array}$ & $\begin{array}{l}\text { Core: } 0.55 \\
\text { Wrap: } 0.23\end{array}$ & $\begin{array}{l}\text { Core: } 630 \pm 25 \\
\text { Wrap: } 21960 \pm 1200\end{array}$ \\
\hline $\mathrm{D}$ & $\begin{array}{l}\text { Polyethylene } \\
\text { terephthalate (PET) }\end{array}$ & UHMWPE & $\begin{array}{l}\text { Monofilament core and } \\
\text { multifilament wrap }\end{array}$ & $\begin{array}{l}\text { Core: } 0.70 \\
\text { Wrap: } 0.23\end{array}$ & $\begin{array}{l}\text { Core: } 420 \pm 30 \\
\text { Wrap: } 21960 \pm 1200\end{array}$ \\
\hline $\mathrm{E}$ & PU & Co-polymer polyamide (CPPA) & $\begin{array}{l}\text { Monofilament core and } \\
\text { monofilament wrap }\end{array}$ & $\begin{array}{l}\text { Core: } 0.65 \\
\text { Wrap: } 0.18\end{array}$ & $\begin{array}{l}\text { Core: } 114 \pm 20 \\
\text { Wrap: } 2355 \pm 1500\end{array}$ \\
\hline $\mathrm{F}$ & PET & CPPA & $\begin{array}{l}\text { Monofilament core and } \\
\text { monofilament wrap }\end{array}$ & $\begin{array}{l}\text { Core: } 0.70 \\
\text { Wrap: } 0.18\end{array}$ & $\begin{array}{l}\text { Core: } 420 \pm 30 \\
\text { Wrap: } 2355 \pm 1500\end{array}$ \\
\hline
\end{tabular}


Table 2. Summary of loads that were selected for the cross sectional images.

\begin{tabular}{ll}
\hline Yarn & Load $(\mathrm{N})$ \\
\hline A & $6,15,30,40$ and 48. \\
B & $10,30,50$ and 70. \\
C & $20,35,50$ and 65. \\
D & 15,30 and 45. \\
E & $7,15$. \\
F & 10,15 and 20. \\
\hline
\end{tabular}

Table 3. Diameter of the yarn A under different load was measured by the external and the cross-sectional images.

\begin{tabular}{lcc}
\hline Load $(\mathrm{N})$ & $\begin{array}{c}\text { Diameter of yarn obtained } \\
\text { from external images } \\
\end{array}$ & $\begin{array}{c}\text { Diameter of yarn obtained } \\
\text { from cross-sectional images }\end{array}$ \\
\hline 6 & 0.723 & 0.711 \\
15 & 0.748 & 0.731 \\
30 & 0.752 & 0.797 \\
40 & 0.748 & 0.794 \\
48 & 0.773 & 0.841 \\
\hline
\end{tabular}


Table 4. Summary of mechanical properties of core, wrap and yarn.

\begin{tabular}{|c|c|c|c|c|}
\hline Yarn & $\begin{array}{l}\text { Young's modulus of } \\
\text { the core } \\
\qquad(\mathrm{MPa})\end{array}$ & $\begin{array}{l}\text { Young's modulus of } \\
\text { the wrap } \\
\text { (MPa) }\end{array}$ & $\begin{array}{l}\text { Max negative Poisson's } \\
\text { ratio }\end{array}$ & $\begin{array}{l}\text { Strain at max } \\
\text { negative } \\
\text { Poisson's ratio }\end{array}$ \\
\hline $\mathrm{A}$ & PU - 114 20 & $\begin{array}{l}\text { UHMWPE - } 21960 \pm \\
1200\end{array}$ & $-1.65 \pm 0.33$ & 0.09 \\
\hline $\mathrm{E}$ & PU - 114 20 & $\begin{array}{l}\text { Co-polymer } \\
\text { polyamide - } 2355 \\
\pm 1500\end{array}$ & $-5.58 \pm 0.47$ & 0.008 \\
\hline B & $P A-260 \pm 40$ & $\begin{array}{l}\text { UHMWPE }-21960 \pm \\
1200\end{array}$ & $-1.67 \pm 0.27$ & 0.09 \\
\hline $\mathrm{F}$ & PET - $420 \pm 30$ & $\begin{array}{l}\text { Co-polymer } \\
\text { polyamide - } 2355 \\
\pm 1500\end{array}$ & $-0.39 \pm 1.01$ & 0.21 \\
\hline D & PET $-420 \pm 30$ & $\begin{array}{l}\text { UHMWPE - } 21960 \pm \\
1200\end{array}$ & $-13.52 \pm 3.78$ & 0.02 \\
\hline $\mathrm{C}$ & $P E-630 \pm 25$ & $\begin{array}{l}\text { UHMWPE }-21960 \pm \\
1200\end{array}$ & $-2.22 \pm 0.47$ & 0.06 \\
\hline
\end{tabular}


(a)

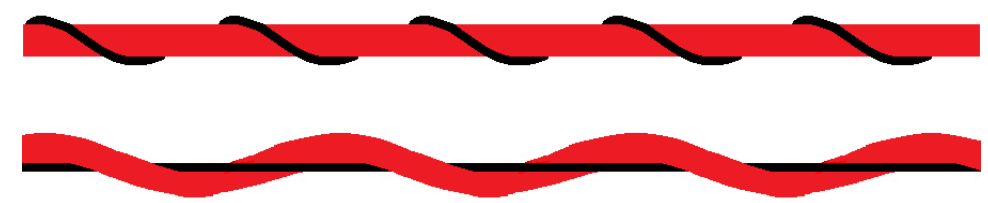

(b)
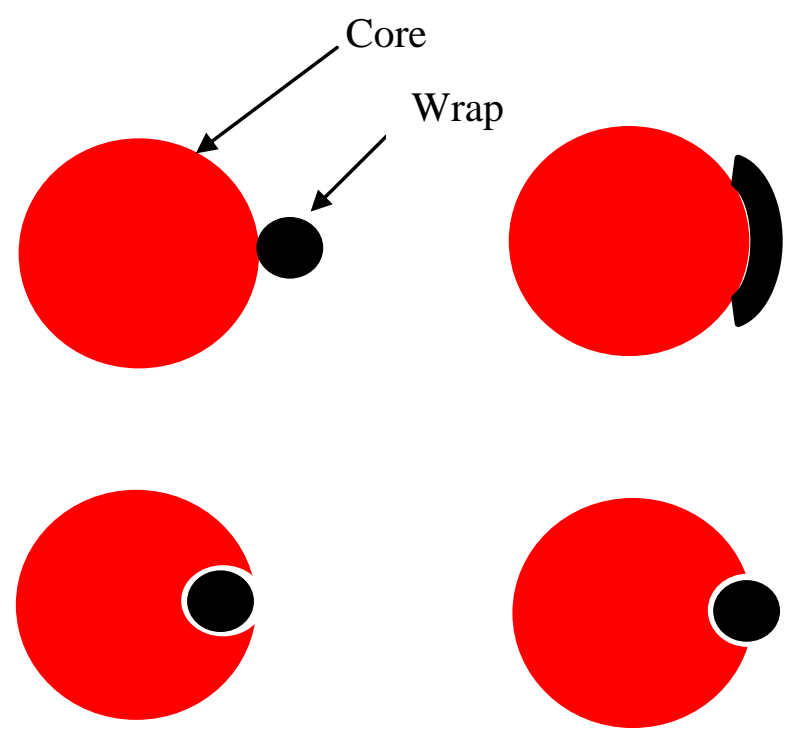

(c)

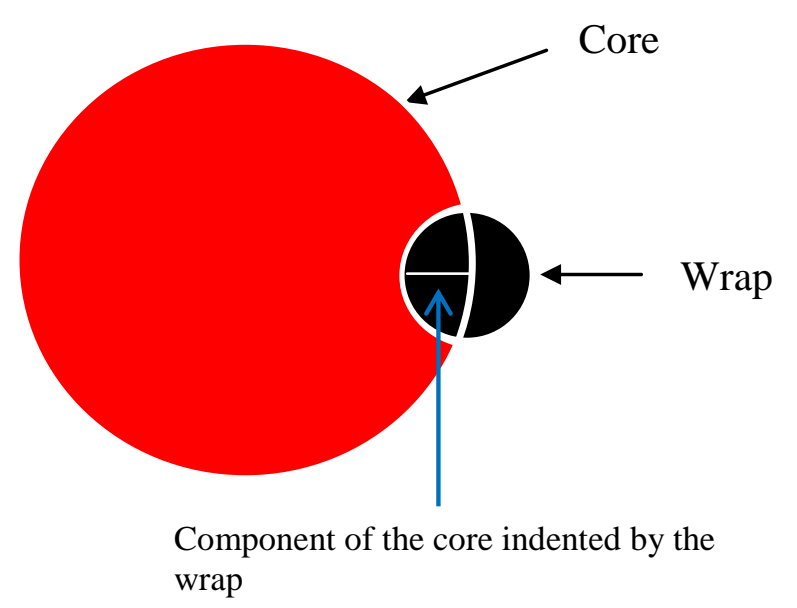

Fig. 1. (a) HAY at zero strain and at maximum strain. (b) Cross-section of HAY (clockwise): Ideal case, the wrap spread around the core, partial core-indentation and entire coreindentation. (c) Component of the wrap embeded into the core. 


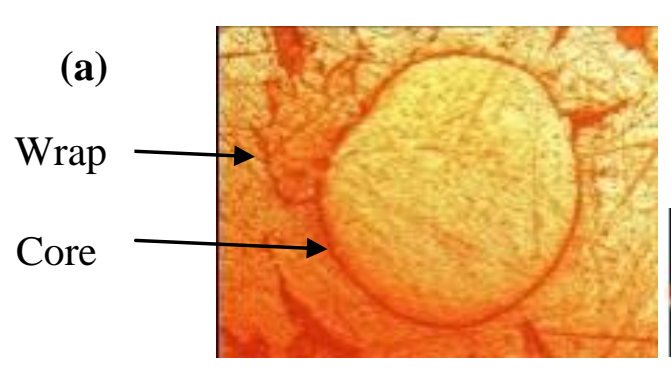

(b)

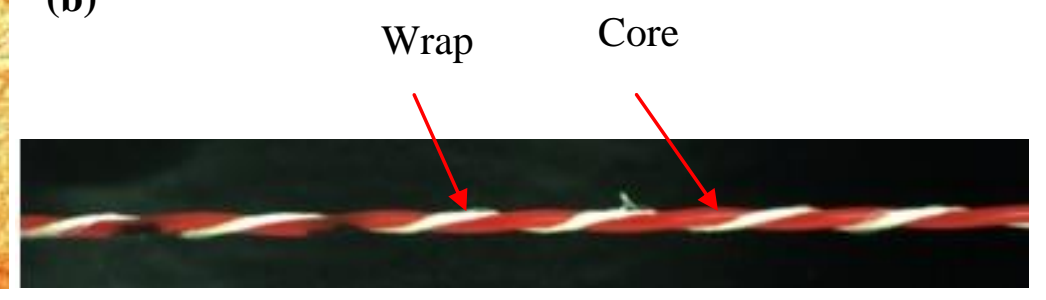

(c)

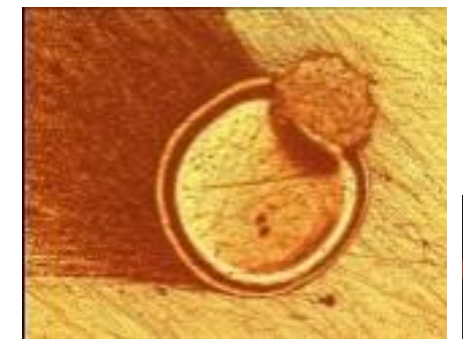

(d)

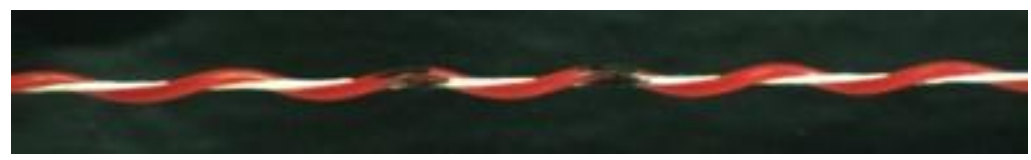

(e)

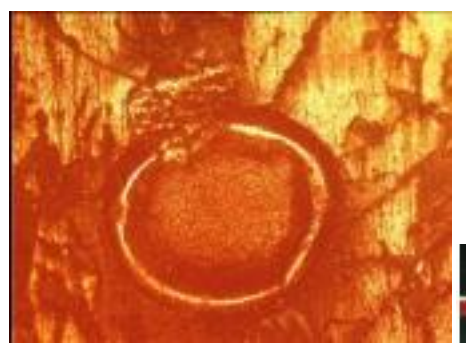

(f)

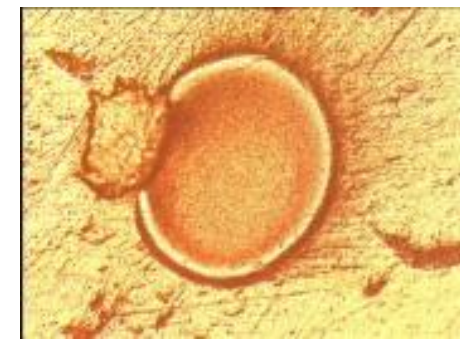

(h)

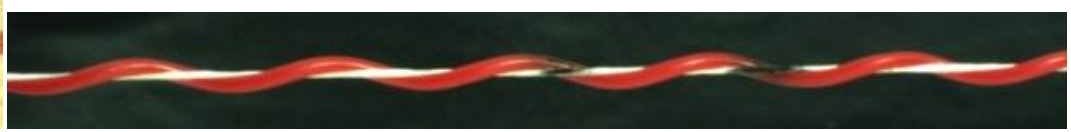

(i)

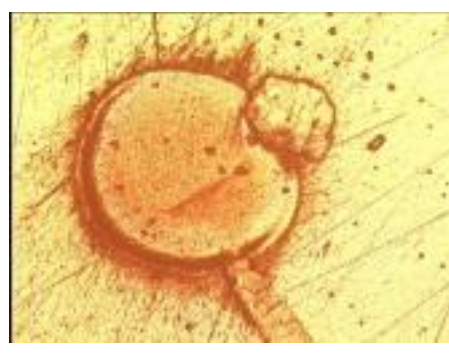

(j)

Fig. 2. (a and b) Cross-sectional and external images at 6N. (c and d) Cross-sectional and external images at $15 \mathrm{~N}$. (e and f) Cross-sectional and external images at $30 \mathrm{~N}$. (g and h)

Cross-sectional and external images at 40 N. (i and j) Cross-sectional and external image at $48 \mathrm{~N}$. 


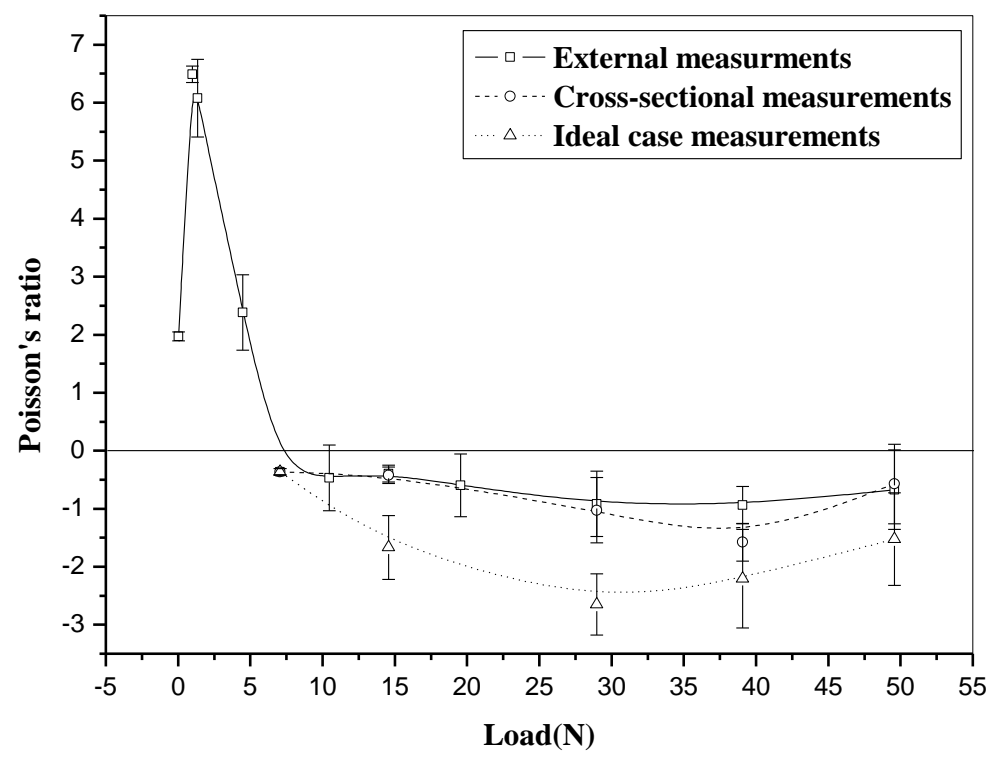

Fig. 3. Poisson's ratio as a function of load for yarn A. 1) External measurements, transverse and longitudinal strain obtained from the external image taken during tensile testing; 2)

Cross-sectional measurements, transverse strain obtained from the cross-sectional image and longitudinal strain obtained from the external image; 3) Ideal case measurements, transverse strain of the yarn with hypothetically no indentation of the core measured from the modified cross sectional image, and longitudinal strain from the external image. 

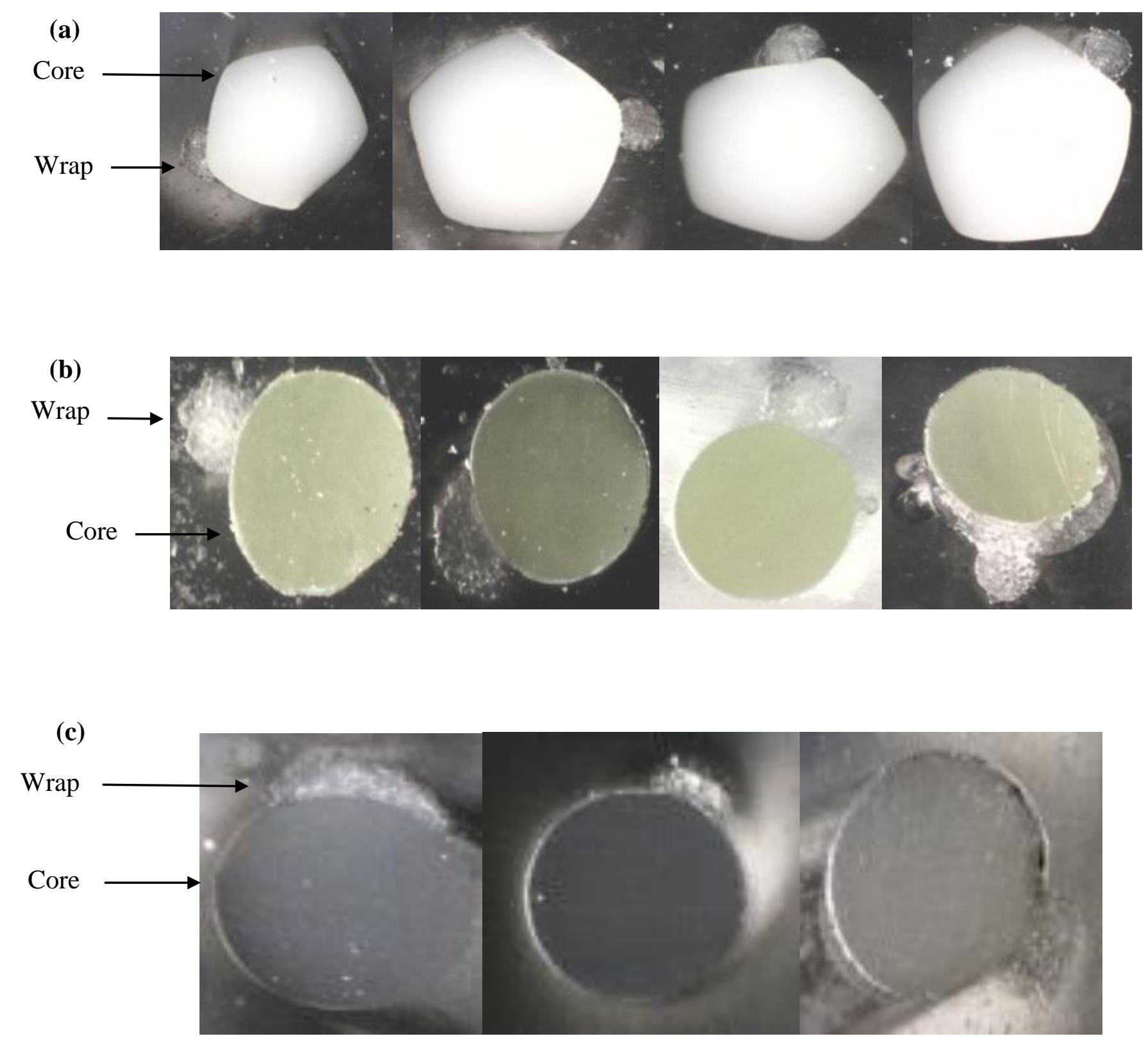

Fig. 4. (a) Cross-sectional image of yarn B at 10, 30, 50 and $70 \mathrm{~N}$ respectively. (b) Crosssectional image of yarn $\mathrm{C}$ at 20,35, 50 and $65 \mathrm{~N}$ respectively. (c) Cross-sectional image of yarn $\mathrm{D}$ at 15,30 and $45 \mathrm{~N}$ respectively. 


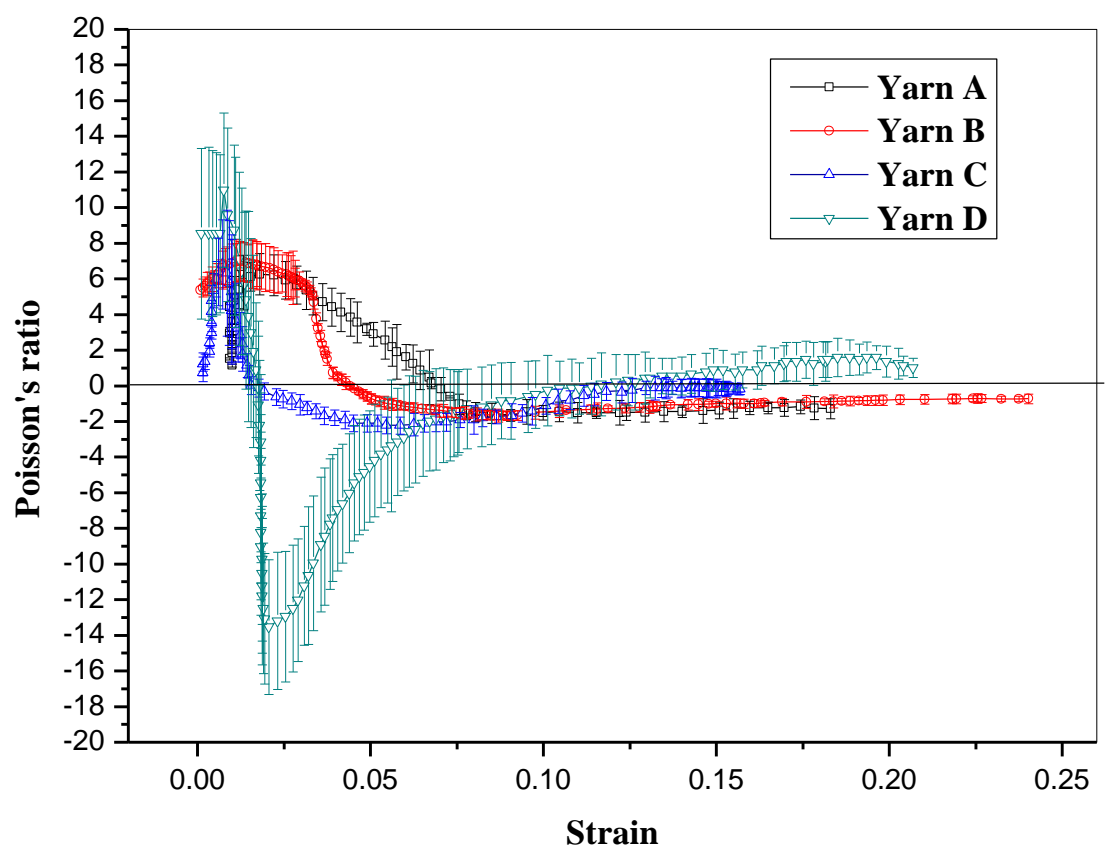

Fig. 5. Poisson's ratio of yarn A, B, C and D as function of strain.

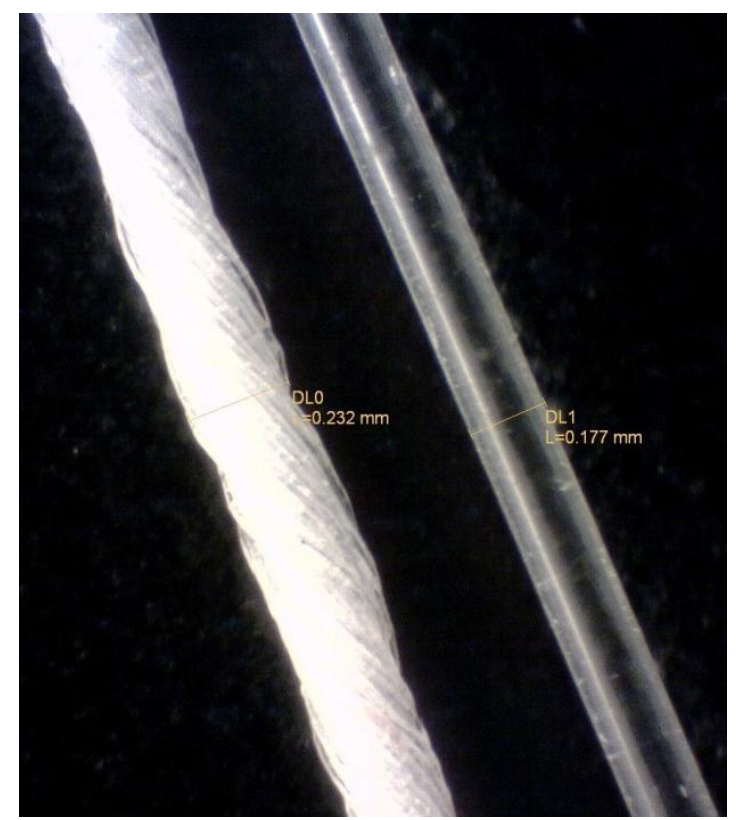

Fig. 6. Micrographs of multifilament UHMWPE and monofilament CPPA wrap fibres. 


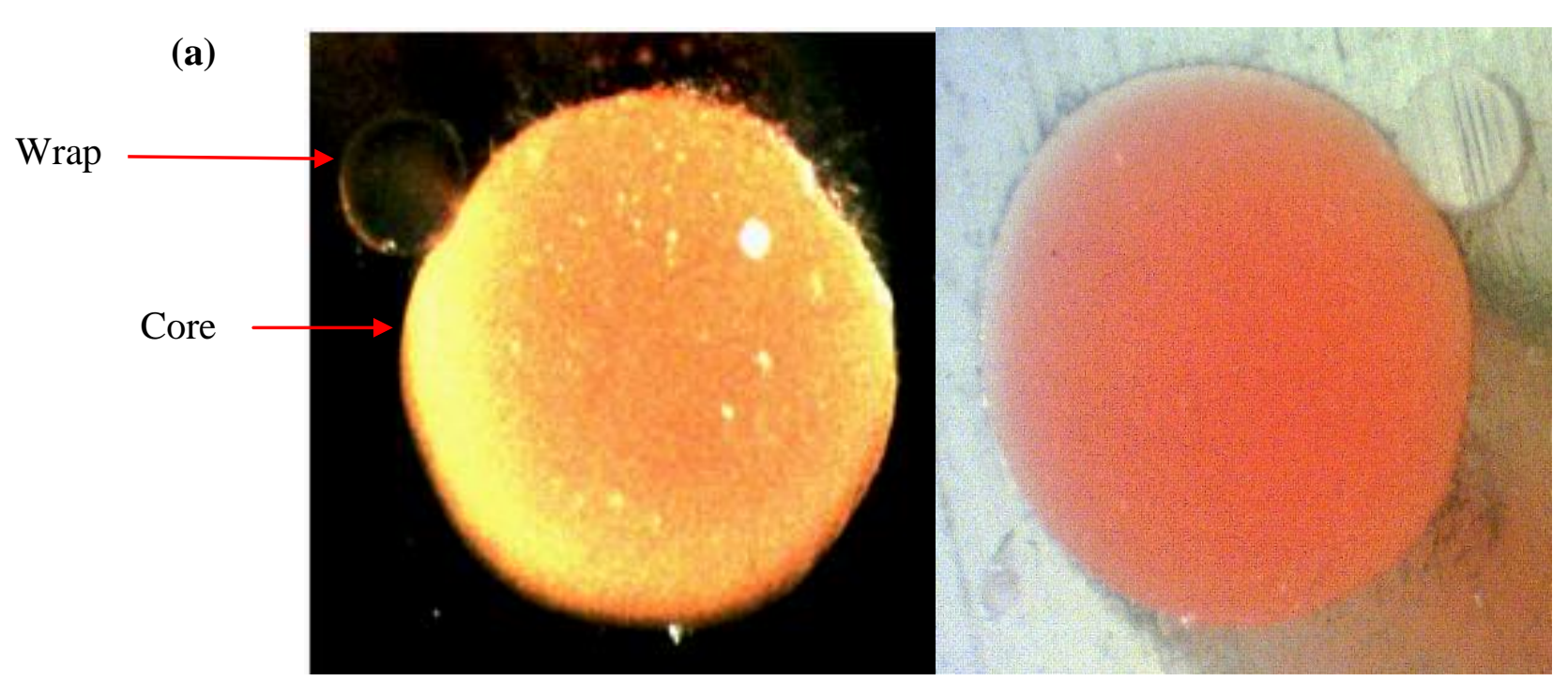

(b)

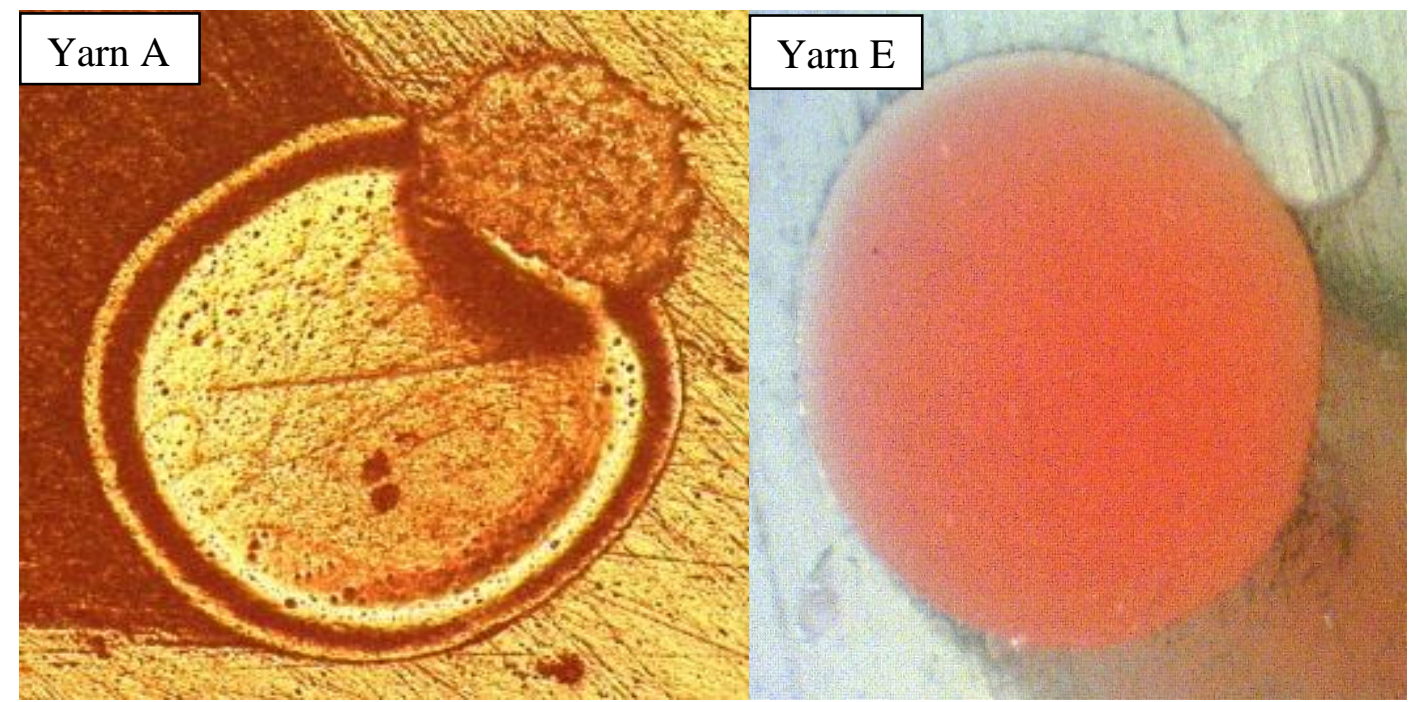

Fig. 7. (a) Cross-sectional image of yarn E at 7 and 15 N. (b) Comparison between cross section of yarn $\mathrm{A}$ and $\mathrm{E}$ at $15 \mathrm{~N}$ load and 60 times magnification. 


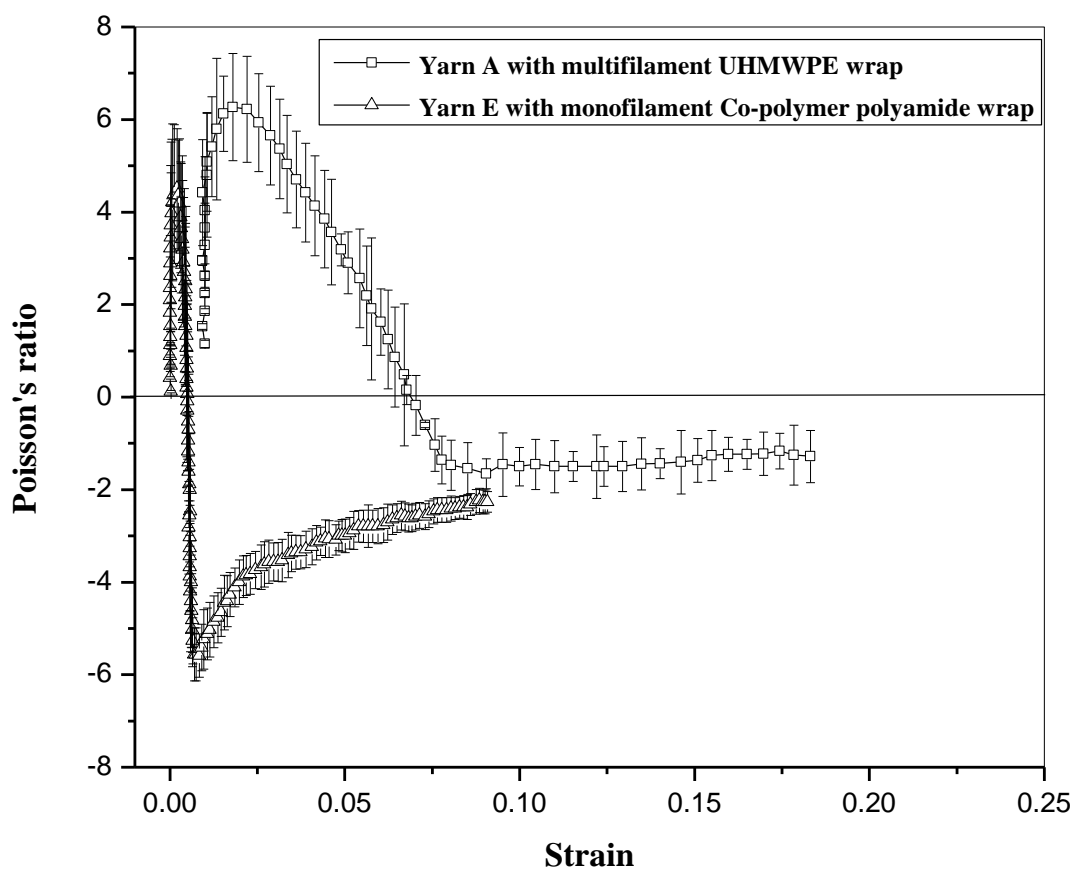

Fig. 8. Poisson's ratio of yarn A and $\mathrm{E}$ as a function of strain. 
(a)

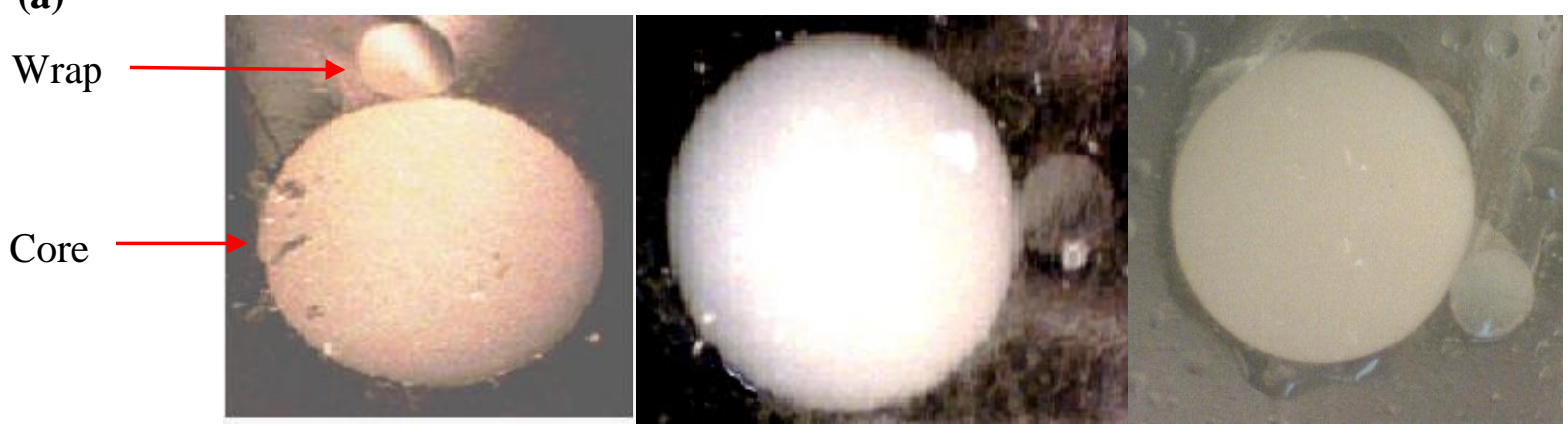

(b)

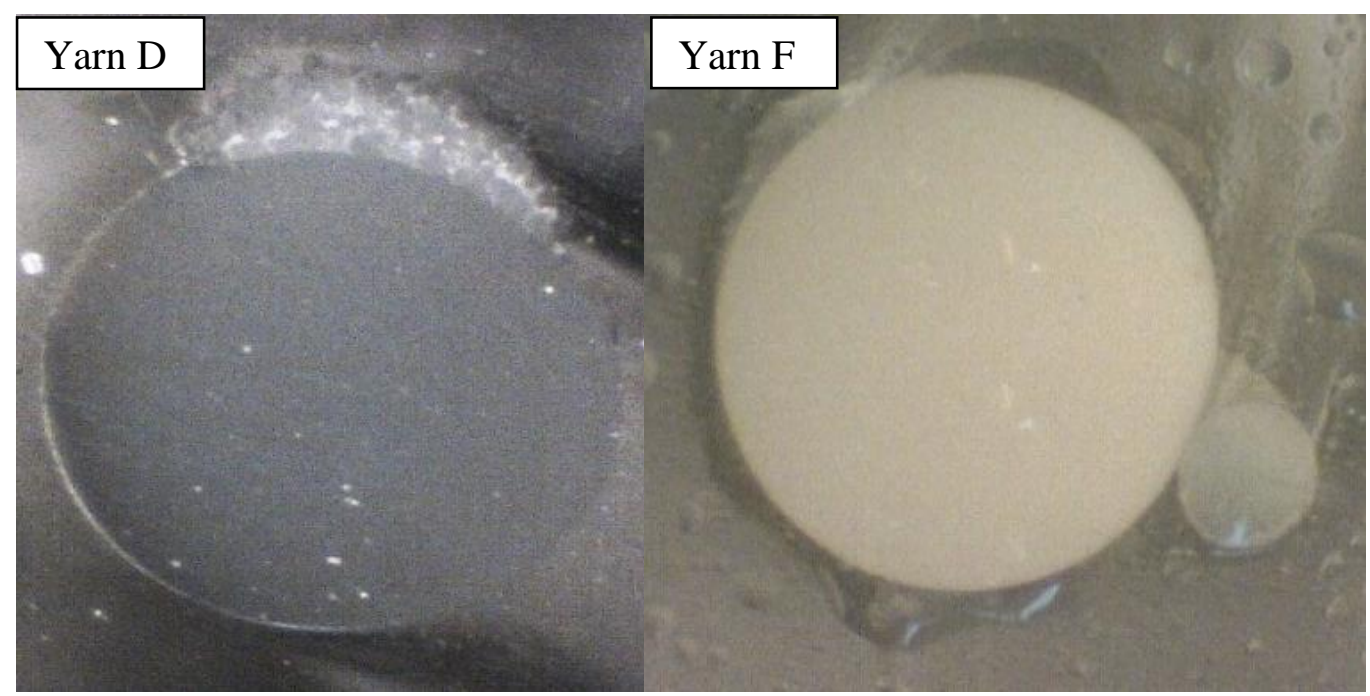

Fig. 9. (a) Cross-sectional image of yarn $\mathrm{F}$ at 10, 15 and $20 \mathrm{~N}$ respectively. (b) Comparison between cross section of yarn D and $\mathrm{F}$ at 15 and $20 \mathrm{~N}$ under 60 times magnification. 


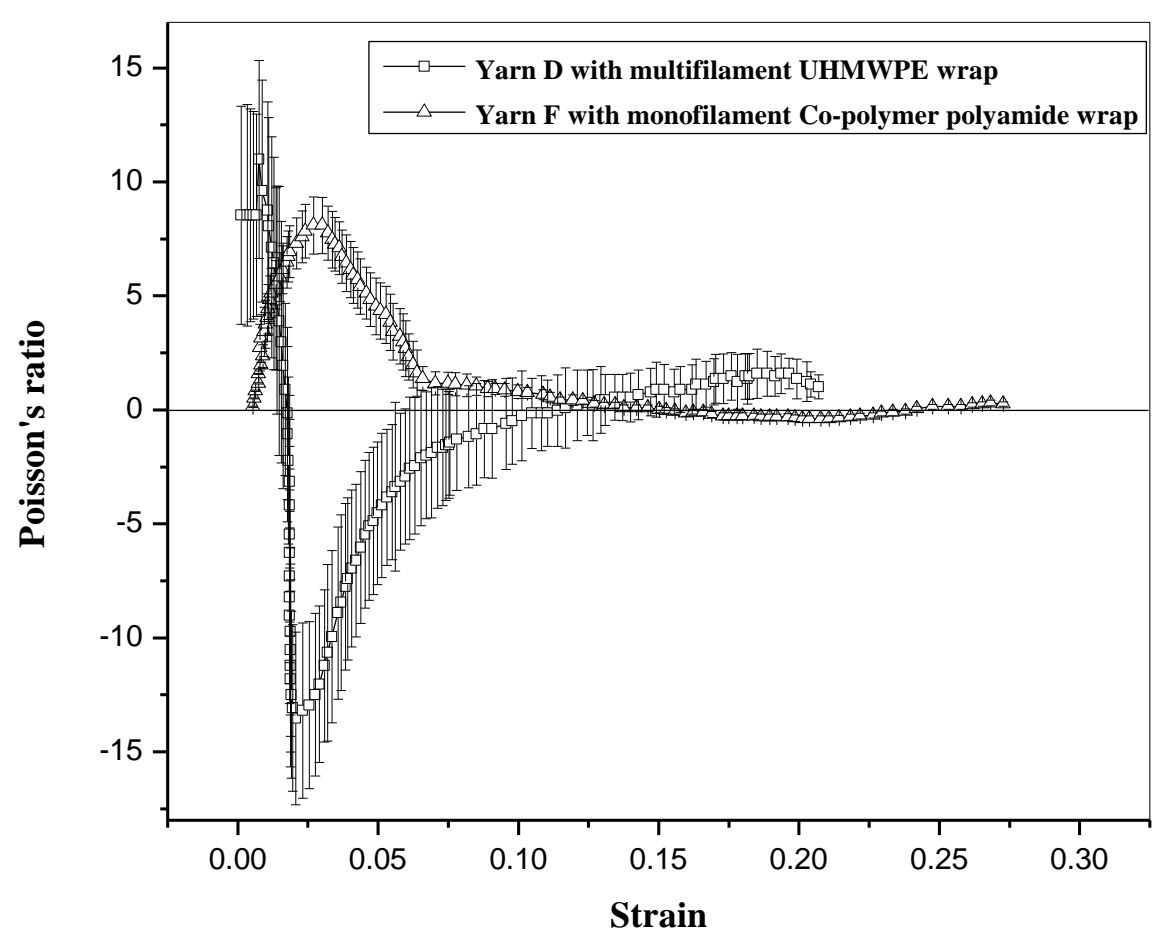

Fig. 10. Poisson's ratio of yarn D and F as a function of strain. 